\title{
Reference evapotranspiration modeling using radial basis function neural network in different agro-climatic zones of Chhattisgarh
}

\author{
DIWAKAR NAIDU ${ }^{1,2^{*}}$ and BABITA MAJHI \\ 'Guru Ghasidas Vishwavidyalaya, Central University, Bilaspur (C.G.)-495009, India \\ ${ }^{2}$ BRSM College of Agricultural Engineering and Technology and Research Station, \\ Indira Gandhi Krishi Vishwavidyalaya, Mungeli, (C.G) India \\ *Corresponding author: dnaidu1971@gmail.com
}

\begin{abstract}
Precise estimation of evapotranspiration (ET) is extremely essential for efficient utilization of available water resources. Among the empirical models, FAO-Penman-Monteith equation (FAO-PM) is considered as standard method to determine reference evapotranspiration $\left(\mathrm{ET}_{0}\right)$. In developing countries like India, application of FAO-PM equation for $\mathrm{ET}_{0}$ estimation has certain limitations due to unavailability of specific data requirements. Several empirical models such as Hargreaves, Turc, Blaney-Criddle etc., are also considered for $\mathrm{ET}_{0}$ estimation. However, $\mathrm{ET}_{0}$ estimates obtain with these models are not comparable with benchmark FAO-PM ET . To address this issue, potential of radial basis function neural network (RBFNN) is investigated to estimate FAO-PM ET . Result obtained with proposed RBFNN models are compared with equivalent multi-layer artificial neural network (MLANN) and empirical approach of Hargreaves, Turc and Blaney-Criddle. Lower RMSE values obtained with RBFNN and MLANN models is an indication of improved performance over empirical models. Similarly, higher $\mathrm{R}^{2}$ and Efficiency Factor obtained with RBFNN and MLANN models also approves the superiority of machine learning techniques over empirical models. Among the two machine learning techniques, RBFNN models performed better as

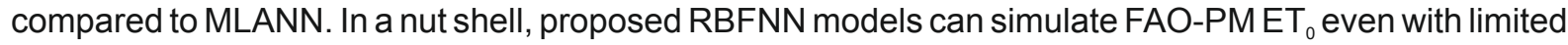
meteorological parameters and consistence degree of accuracy level.
\end{abstract}

Keywords: $\mathrm{ET}_{0}$ estimation, FAO-PM ET ${ }_{0}, \mathrm{RBFNN}, \mathrm{MLANN}$, empirical models

Evapotranspiration (ET) is considered as one of most important parameter for agro-climatic analyses such as determination of crop water requirement and computation of water balance parameters. ET being an extremely complex non-linear process in nature, it is always very difficult to measure it. Therefore, consumptive use of water from a reference crop under non limiting conditions with weather parameters being the only factor affecting the process is computed by means of empirical models and termed as reference ET $\left(\mathrm{Et}_{0}\right)$. Several empirical models have been developed in the past to determine $\mathrm{ET}_{0}$. Among the empirical models, Food and Agricultural Organization has recommended Penman-Monteith equation (FAO-PM) as standard method for $\mathrm{ET}_{0}$ estimation (Allen et al. 1998). FAOPM equation requires meteorological parameters such as temperature, humidity, wind speed, sunshine hours and net radiation to determine $\mathrm{ET}_{0}$. Empirical models like Hargreaves, Turc, Open Pan, Blaney-Criddle and Christianson etc., have also been used by several working as they require less number of meteorological parameters (Dar et al. 2017; Phad et al.
2019). However, $\mathrm{ET}_{0}$ estimates obtained using these models is not comparable with FAO-PM as these methods yield large error and hence their application becomes limited.

Application of data-driven machine learning techniques such as fuzzy logic, artificial neural network and evolutionary computation are increasingly gaining popularity in the recent decade and emerged as alternate approach for FAO-PM $\mathrm{ET}_{0}$ estimation with higher order accuracy as compared to equivalent empirical methods. (Chauhan and Shrivastava 2009; Mallikarjuna et al. 2012, Khedkar et al. 2019). A study conducted by Landeras et al. (2008) on comparison between ANN models and empirical equations for daily $\mathrm{ET}_{0}$ estimation in the Basque Country (Northern Spain) confirms the superiority of ANN models over empirical equations. Study conducted by Feng et al. (2016) for estimating FAO-PM ET $\mathrm{E}_{0}$ in humid region of Southwest China reveals that extreme learning machine (ELM) and artificial neural network optimized by genetic algorithm (GANN) based models produced better estimates than wavelet neural network (WNN) and empirical approaches of Hargreaves, 
Makkink, Priestley-Taylor and Ritchie models. Gocić et al. (2015) has reported support vector machine-wavelet (SVMWavelet) as the best method for $\mathrm{ET}_{0}$ prediction. SVM-Wavelet and support vector machine-firefly algorithm (SVM-FFA) methods produced higher correlation coefficient with $\mathrm{ET}_{0}$ as compared to Artificial Neural network (ANN) and Genetic programming (GP) computational methods. Shiri et al. (2014) has computed $\mathrm{ET}_{0}$ estimates using heuristic data driven (HDD) models such as ANN, ANFIS, SVM and gene expression programming (GEP) for a wide range of weather stations in Iran and compared the same with corresponding empirical models (Hargreaves-Samani, Makkink, Priestley-Taylor and Turc). They have found that HDD models generally outperformed empirical models, whereas among the HDD models GEP-based model produced higher accuracy.

Literature review discussed above, motivated us to conduct present investigation with an objective to demonstrate the ability of radial basis function neural network (RBFNN) for computing weekly FAO-PM ET $\mathrm{ET}_{0}$ estimates in three agroclimatic zones (ACZs) of Chhattisgarh. The material and methods section provides the details of the study area, architecture of RBFNN and MLANN and performance evaluation criteria. The results obtained based on simulation studies are discussed in the subsequent section. Significant finding of the study are given in the concluding section.

\section{MATERIALS AND METHODS}

\section{Studyarea}

The present investigation is aimed at estimating weekly FAO-PM ET ${ }_{0}$ using RBFNN for three representative stations, i.e. Raipur, Jagdalpur and Ambikapur located in Chhattisgarh Plains, Bastar Plateau and Northern Hills ACZs respectively in the Chhattisgarh state of east central India with available climatic data. Climate of Chhattisgarh is moist sub humid in general with an average annual rainfall of 1200-1400 mm and $\mathrm{ET}_{0}$ losses between 1400-1600 mm in different ACZs. Long term weekly meteorological data of Raipur (1981-2015), Jagdalpur(1993-2017) and Ambikapur(1999-2015) have been collected from respective meteorological observatories and their descriptive statistics in terms of weekly averages of maximum temperature $\left({ }^{\circ} \mathrm{C}\right)-\mathrm{T}_{\max }$, minimum temperature $\left({ }^{\circ} \mathrm{C}\right)$ - $\mathrm{T}_{\text {min }}$, relative humidity during morning hours $(\%)-\mathrm{RH}_{1}$, relative humidity during afternoon hours $(\%)-\mathrm{RH}_{2}$, wind speed (kmph) - WS, bright sunshine (hours) - BSS, pan evaporation (mm/week) - EP are shown in Table 1. Weekly totals of $\mathrm{ET}_{0}$ are computed using FAO-PM (Allen et al. 1998) and considered as benchmark for model calibration and validation purposes.

\section{Radial basis function neural network (RBFNN) based estimator}

RBFNN is a category of feed forward network with single hidden layer and an output layer formulated by Broomhead and Lowe (1988). Pictorial representation of the RBFNN is given in Fig.1. Each processing unit termed as neuron in the hidden layer is associated with centers $c=c_{1}, c_{2}$, $c_{3} \ldots \ldots c_{h}$ and its width $\sigma=\sigma_{1}, \sigma_{2}, \sigma_{3} \ldots . \sigma_{h}$, where $h$ is the number of neuron in the hidden layer. Each neuron in hidden layer receives the same set of input data $\left(x=x_{1}, x_{2}, x_{3} \ldots x_{n}\right)$ Centers of every hidden neuron have the same dimension as that of the input data, $c_{i} \in R^{n}, x \in R^{n}$. The output of each hidden layer neurons $\emptyset_{1}, \emptyset_{2}, \emptyset_{3} \ldots \emptyset_{h}$ is associated with synaptic weight $\left(w=w_{1}, w_{2}, w_{3} \ldots \ldots w_{h}\right)$.

Output $\emptyset_{i}$ of $i^{\text {th }}$ hidden layer neuron is basically a Gaussian function and is represented by:

$\emptyset_{i}(z)=e^{\frac{-z^{2}}{2 \sigma_{i}^{2}}}$

where, $z=|| x-c_{i} \| \mid$ represents the Euclidian distance between input data and corresponding centers and $\emptyset_{i}=\varnothing\left(|| x-c_{i}||\right.$. The Gaussian function used in the each hidden layer neuron is actually a category of radial basis function. Finally the response of the RBFNN for a given set of input data at the output layer neuron is linear in terms of weights and computed using the following expression.

$y=\sum_{i=1}^{h} w_{i} \emptyset_{i}$

Calibration of the RBFNN network for each instant of input data and its corresponding output $\{x, y\}$ is done in recursive manner by updating the network parameters $\left\{w_{i}, c_{i}\right.$ $\mathrm{s}_{i}$ \} to minimizing the following instantaneous error cost function.

$e=\frac{1}{2}\left(y^{d}-y\right)^{2}$

The weight update rules to optimize the network parameters $\left\{w_{i}, c_{i} \mathrm{~s}_{i}\right\}$ at time $\mathrm{t}$ is given by following equations which are derived using gradient descent algorithm.

$w_{i}(t+1)=w_{i}(t)+\eta_{1}\left(y^{d}-y\right) \emptyset_{i}$

$c_{i j}(t+1)=c_{i j}(t)+\frac{\eta_{2}}{\sigma_{i}^{2}}\left(y^{d}-y\right) w_{i} \emptyset_{i}\left(x_{j}-c_{i j}\right)$

$\sigma_{i}(t+1)=\sigma_{i}(t)+\frac{\eta_{3}}{\sigma_{i}^{3}}\left(y^{d}-y\right) w_{i} \emptyset_{i} z_{i}^{2}$

$c_{i j}=j^{\text {th }}$ element of $i^{\text {th }}$ center

$\eta_{1}, \eta_{2}, \eta_{3}=$ learning rate for network parameters $\left\{w_{i}, c_{i}, \sigma_{i}\right\}$ respectively. 
Table 1: Descriptive statistics of weekly meteorological parameters at Raipur, Jagdalpur and Ambikapur

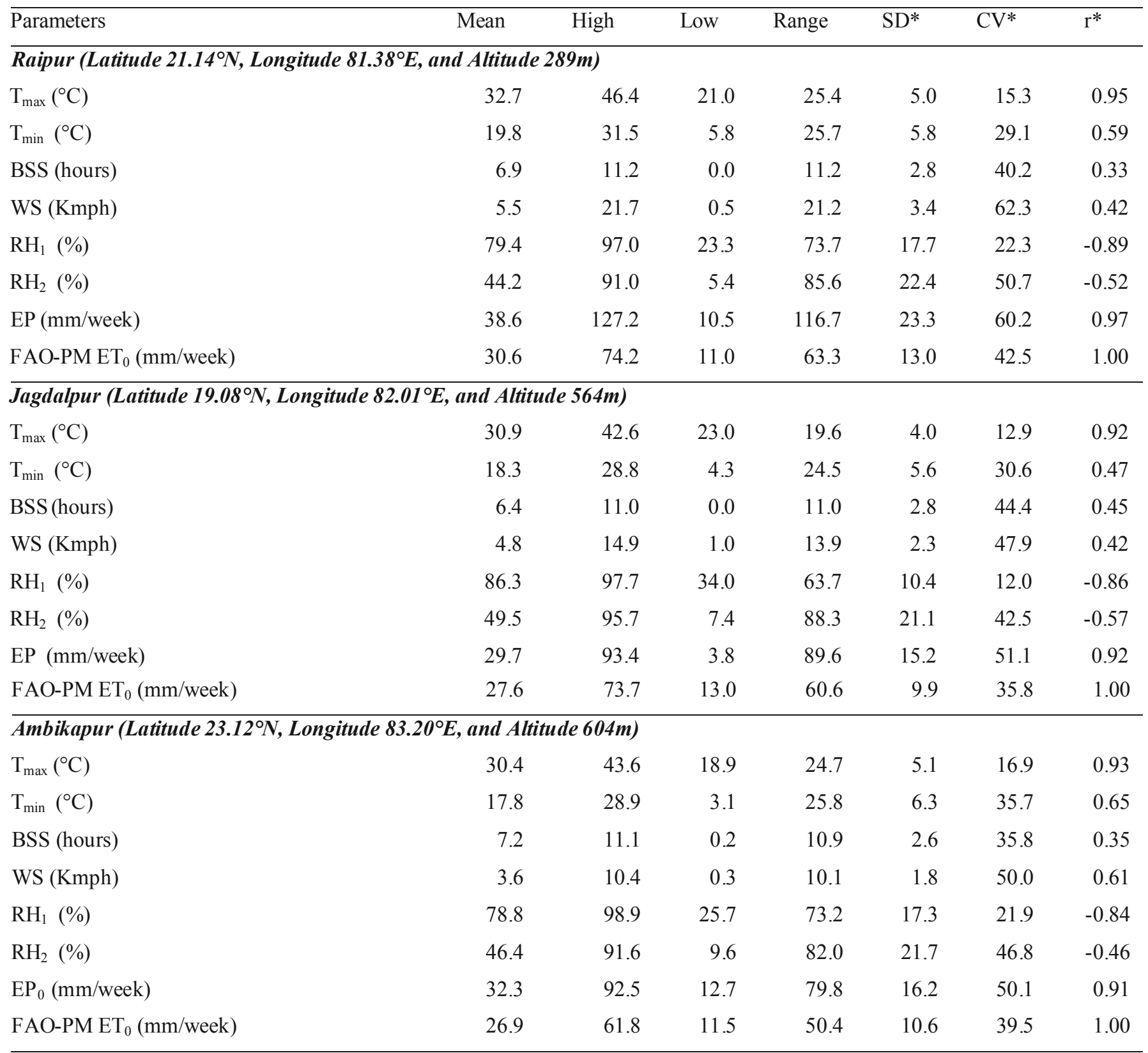

Table 2: Details of empirical models used to compute $\mathrm{ET}_{0}$.

\begin{tabular}{lc}
\hline Empirical models & Input combination used in the software \\
\hline Hargreaves (Hargreaves et al., 1985) & $\mathrm{T}_{\max }, \mathrm{T}_{\min }$ \\
Turc (Turc, 1961) & $\mathrm{T}_{\max }, \mathrm{T}_{\min }, \mathrm{BSS}$ \\
Blaney-Criddle (Doorenbos and Pruitt, 1977) & $\mathrm{T}_{\max }, \mathrm{T}_{\min }, \mathrm{RH}_{1} \& \mathrm{RH}_{2}, \mathrm{WS}, \mathrm{BSS}$ \\
FAO Penman - Monteith (Allen et al., 1998) & $\mathrm{T}_{\max }, \mathrm{T}_{\min }, \mathrm{RH}_{1} \& \mathrm{RH}_{2}, \mathrm{WS}, \mathrm{BSS}$ \\
\hline
\end{tabular}


Table 3: Input combinations used in RBFNN and equivalent MLANN and empirical models.

\begin{tabular}{|c|c|c|c|c|}
\hline \multicolumn{3}{|c|}{ Models } & \multirow[t]{2}{*}{ Input combinations } & \multirow{2}{*}{$\begin{array}{l}\text { No. of } \\
\text { inputs }\end{array}$} \\
\hline RBFNN & MLANN & Empirical & & \\
\hline RBFNN-1 & MLANN-1 & Hargreaves & $\mathrm{T}_{\max }, \mathrm{T}_{\min }$ & 2 \\
\hline RBFNN-2 & MLANN-2 & Turc & $\mathrm{T}_{\max }, \mathrm{T}_{\min }, \mathrm{BSS}$ & 3 \\
\hline RBFNN-3 & MLANN-3 & Blaney-Criddle & $\mathrm{T}_{\max }, \mathrm{T}_{\min }, \mathrm{RH}_{1} \& \mathrm{RH}_{2}, \mathrm{WS}, \mathrm{BSS}$ & 6 \\
\hline
\end{tabular}

Table 4: Parameters of the proposed RBFNN and MLANN models used in the simulation

\begin{tabular}{lcc}
\hline Parameters & Proposed RBFNN & MLANN \\
\hline Number of Input features & $2,3 \& 6$ & $2,3 \& 6$ \\
Number of centers and their corresponding width & 30 & - \\
Number of neurons in hidden layer & 30 & 5 \\
Number of neurons in output layer & 1 & 1 \\
Normalization of input features & -1 to 1 & -1 to 1 \\
Convergence coefficients & $\mathrm{h}_{5}=\mathrm{h}_{6}=\mathrm{h}_{7}=0.01$ & $\mathrm{~h}=0.01$ \\
Activation function & Gaussian & Hyperbolic tangent (tanh) \\
Learning algorithm & RBF update rules & Back propagation
\end{tabular}

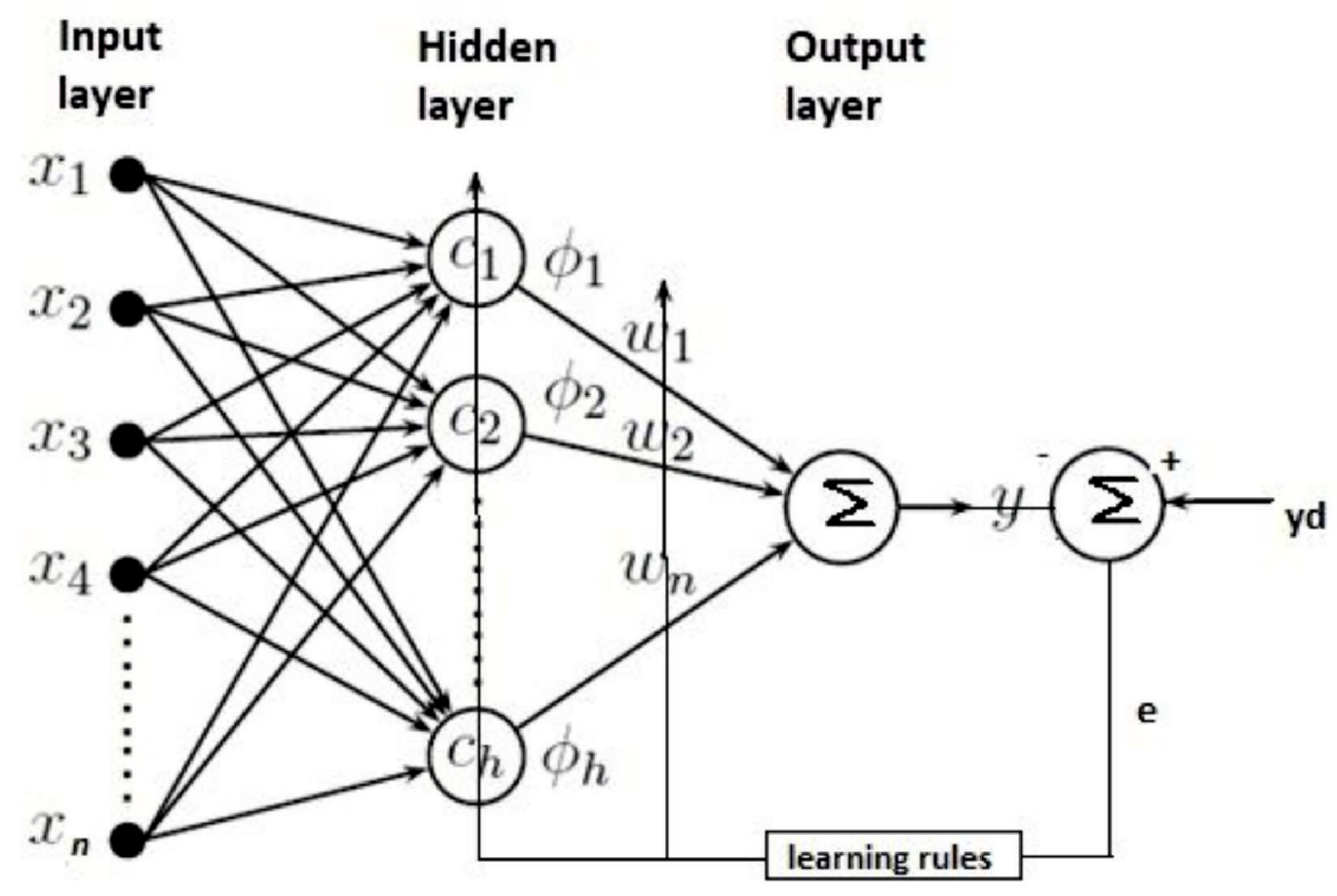

Fig. 1: Block diagram of RBFNN based estimator 


\section{Multi-layer artificial neural network (MLANN)}

MLANN is a feed forward neural network suggested by Haykin (1998) with an input layer, one or more hidden layer and an output layer. A N-5-1 structure of MLANN (N=2,3 \& 6 represents number of input data, 5 neurons in hidden layer and one neuron at the output layers) is used in this study with different input combinations. The training of the network is done by back-propagation algorithm which is based on the error-correcting learning rule to update the weights and biases of each neuron in different layers. Hyperbolic tangent (tanh) is used as the activation function.

\section{Empirical models}

The PET Calculator V3.0 software developed by AICRPAM, CRIDA, Hyderabad is used to estimate $\mathrm{ET}_{0}$ by different empirical approaches. This software is a freeware and computes daily, weekly and monthly $\mathrm{ET}_{0}$ using different input combination of climatic data. More details regarding empirical approaches considered for this investigation may be obtained from the references listed in Table 2.

\section{Performance evaluation measures}

Validation performance of the predictive models are evaluated by computing root mean square error (RMSE), coefficient of determination $\left(\mathrm{R}^{2}\right)$ and efficiency factor proposed by Nash and Sutcliffe, 1970 (EF) between desired (FAO-PM) and estimated $\mathrm{ET}_{0}$. The mathematical formula for the different evaluation measures are as follows.

$$
\begin{aligned}
& R M S E=\sqrt{\frac{1}{T} \sum_{i=1}^{T}\left(\text { Out }_{\text {est }}-O u t_{\text {obs }}\right)^{2}} \\
& R^{2}=\frac{\left(\sum_{i=1}^{T}\left(O u t_{o b s}-\overline{O u t_{o b s}}\right)\left(\text { Out }_{\text {est }}-\overline{\text { Out }_{\text {est }}}\right)\right)^{2}}{\sum_{i=1}^{T}\left(\mathrm{Out}_{\text {obs }}-\overline{\mathrm{Out}_{\text {obs }}}\right)^{2} \sum_{i=1}^{T}\left(\mathrm{Out}_{\text {est }}-\overline{\mathrm{Out}_{\text {est }}}\right)^{2}} \\
& E F=1-\frac{\sum_{i=1}^{T}\left(O u t_{e s t}-O u t_{o b s}\right)^{2}}{\sum_{i=1}^{T}\left(O u t_{o b s}-\overline{O u t_{o b s}}\right)^{2}} \quad(-\infty \leq \mathrm{EF} \leq 1)
\end{aligned}
$$

where, Out $t_{\text {obs }}$ and $O u t_{\text {est }}$ represent the observed and estimated $\mathrm{ET}_{0}$ values respectively. Tis the total number of validation patterns and $\mathrm{i}$ denotes the number of particular instances. Low RMSE values represent the close association between desired and estimated output. Similarly, $\mathrm{R}^{2}$ and EF values close to 1 are also an indicator of superior predictive ability of the model.

\section{RESULTS AND DISCUSSION}

Proposed RBFNN and corresponding MLANN models are developed in MATLAB. Simulations studies are carried out to investigate the potential of proposed RBFNN models as compared to corresponding MLANN and equivalent empirical models (Hargreaves, Turc and Blaney-

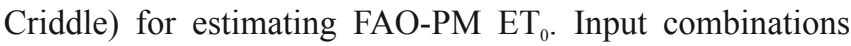
used in proposed RBFNN models are similar to that of equivalent empirical models as shown in Table 3. Long term weekly meteorological data of Raipur (1981-2010), Jagdalpur (1993-2012) and Ambikapur (1999-2012) is used for model calibration, whereas recent 3 to 5 years of data of Raipur (2011-2015), Jagdalpur (2013-2017) and Ambikapur (20132015 ) is used for model validation.

To calibrate the model, input and desired output data is normalized between -1 to 1 . Model parameters of the RBFNN i.e., weights, centers and corresponding width $\left\{w_{i}, c_{i}, \mathbf{S}_{i}\right\}$ are initialized to random numbers between -1 to 1 . Centers have the same dimension as that of input data. Input patterns are given to the input layer of the model in a sequential manner and corresponding estimated output is obtained at the output layer after completion of forward pass for each set of input patterns (Fig. 1). Estimated output is compared with the target output to compute the instantaneous error which is the cost function for the proposed model. Real time update of the model parameters is done in each instance to minimize the squared error. The process continues till all the available input patterns for model calibration gets exhausted. This completes one cycle called epoch. At the end of each epoch, mean square error is computed. The iterative process is repeated several times until MSE is minimized to a desired low value nearly close to zero. This completes the supervised calibration process and model parameters are then fixed to constitute proposed model. Similar calibration process is adopted for MLANN model with corresponding model parameters. The set of parameters which produces optimum results during the simulation study are shown in Table 4 for both the neural network structures.

After completion of model calibration process, validation data sets are used and corresponding estimates of FAO-PM ET ${ }_{0}$ is obtained using the developed models. For model comparison and selection, performance evaluation measures RMSE ( $\mathrm{mm} /$ week), EF and $\mathrm{R}^{2}$ are computed for each model under consideration and results obtained are presented in Table 5 and Table 6 . It is observed that in all most all cases proposed RBFNN models performed better in terms of RMSE in all the three ACZs and ranked first, except in one case at Ambikapur, where RMSE computed with MLANN1 seems to 
Table 5: RMSE $(\mathrm{mm} /$ week) for proposed RBFNN models and corresponding MLANN and equivalent empirical models

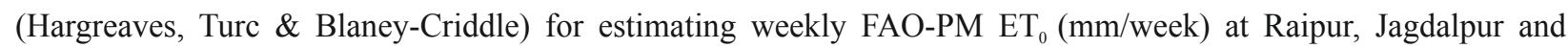
Ambikapur

\begin{tabular}{|c|c|c|c|c|c|c|}
\hline \multirow[t]{2}{*}{ Models } & \multicolumn{2}{|c|}{$\begin{array}{l}\text { Ambikapur } \\
(2013-2015)\end{array}$} & \multicolumn{2}{|c|}{$\begin{array}{c}\text { Jagdalpur } \\
(2013-2017)\end{array}$} & \multicolumn{2}{|c|}{$\begin{array}{c}\text { Raipur } \\
(2011-2015)\end{array}$} \\
\hline & RMSE & Rank & RMSE & Rank & Raipur & Rank \\
\hline Hargreaves & 7.03 & 3 & 7.60 & 3 & 6.22 & 3 \\
\hline MLANN1 & 3.02 & 1 & 5.00 & 2 & 4.10 & 2 \\
\hline RBFNN1 & 3.45 & 2 & 3.62 & 1 & 3.19 & 1 \\
\hline Turc & 3.45 & 2 & 4.17 & 3 & 6.36 & 3 \\
\hline MLANN2 & 2.50 & 1 & 3.10 & 2 & 4.02 & 2 \\
\hline RBFNN2 & 2.50 & 1 & 2.61 & 1 & 3.01 & 1 \\
\hline Blaney-Criddle & 6.01 & 3 & 4.48 & 3 & 6.99 & 3 \\
\hline MLANN3 & 1.82 & 2 & 2.03 & 2 & 1.76 & 2 \\
\hline RBFNN3 & 1.40 & 1 & 1.18 & 1 & 1.43 & 1 \\
\hline
\end{tabular}

Table 6: $\mathrm{R}^{2}$ and EF for proposed RBFNN models in comparison to corresponding MLANN and equivalent empirical models

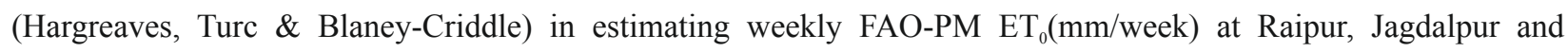
Ambikapur

\begin{tabular}{|c|c|c|c|c|c|c|}
\hline \multirow[b]{2}{*}{ Models } & \multicolumn{3}{|c|}{$\mathrm{R}^{2}$} & \multicolumn{3}{|c|}{$\mathrm{EF}$} \\
\hline & Ambikapur & Jagdalpur & Raipur & Ambikapur & Jagdalpur & Raipur \\
\hline Hargreaves & 0.933 & 0.799 & 0.890 & 0.312 & 0.105 & 0.705 \\
\hline MLANN1 & 0.912 & 0.867 & 0.923 & 0.873 & 0.613 & 0.872 \\
\hline RBFNN1 & 0.869 & 0.867 & 0.929 & 0.834 & 0.797 & 0.923 \\
\hline Turc & 0.912 & 0.805 & 0.825 & 0.835 & 0.731 & 0.691 \\
\hline MLANN2 & 0.942 & 0.934 & 0.938 & 0.913 & 0.851 & 0.877 \\
\hline RBFNN2 & 0.926 & 0.930 & 0.979 & 0.913 & 0.895 & 0.931 \\
\hline Blaney-criddle & 0.810 & 0.847 & 0.821 & 0.497 & 0.689 & 0.628 \\
\hline MLANN3 & 0.964 & 0.956 & 0.941 & 0.954 & 0.936 & 0.976 \\
\hline RBFNN3 & 0.973 & 0.979 & 0.986 & 0.973 & 0.979 & 0.984 \\
\hline
\end{tabular}

be better as compared to RBFNN1. Moreover, proposed RBFNN models found to be superior over equivalent empirical approaches (Hargreaves, Turc and Blaney-Criddle) as RMSE significantly reduced by more than half to three fourth times in most of the cases. Lower RMSE values are highlighted by bold numbers in the Table 5. The magnitude of improvement in RMSE values is more visible in case of Raipur as compared to Ambikapur and Jagdalpur. This may be associated with the topographic situation of respective ACZs and due to availability of more number of input patterns to calibrate the model. A comparison between model estimated

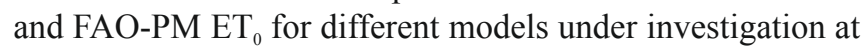
Ambikapur, Jagdalpur and Raipur are illustrated in Figs. 2(a to i), 3(a to i) and 4(a to i) respectively. Large deviations from the FAO-PM ET ${ }_{0}$ can be clearly seen with empirical approaches of
Hargreaves, Turc and Blaney-Criddle in all the three locations particularly for extreme values of $\mathrm{ET}_{0}$, whereas the RBFNN and MLANN estimated $\mathrm{ET}_{0}$ matches closely with the FAO-PM ET $\mathrm{ET}_{0}$ in all locations. However, as compare to MLANN $\mathrm{ET}_{0}$ estimates, the proposed RBFNN estimates

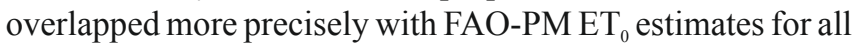
input scenarios.

Two more performance evaluation measures, $\mathrm{R}^{2}$ and EF are also computed for each model as model selection based on $\mathrm{R}^{2}$ alone may mislead sometimes. In general, $\mathrm{R}^{2}$ and $\mathrm{EF}$ value close to one indicates higher prediction accuracy of any regression model. It can be seen from the Table 6 that in most of the cases higher $\mathrm{R}^{2}$ values close to 0.9 or above is obtained and hence, it becomes difficult to choose particular model based on $\mathrm{R}^{2}$ alone. $\mathrm{R}^{2}$ value obtained with Hargreaves model for Ambikapur is 0.933, which is misleading, whereas the EF 

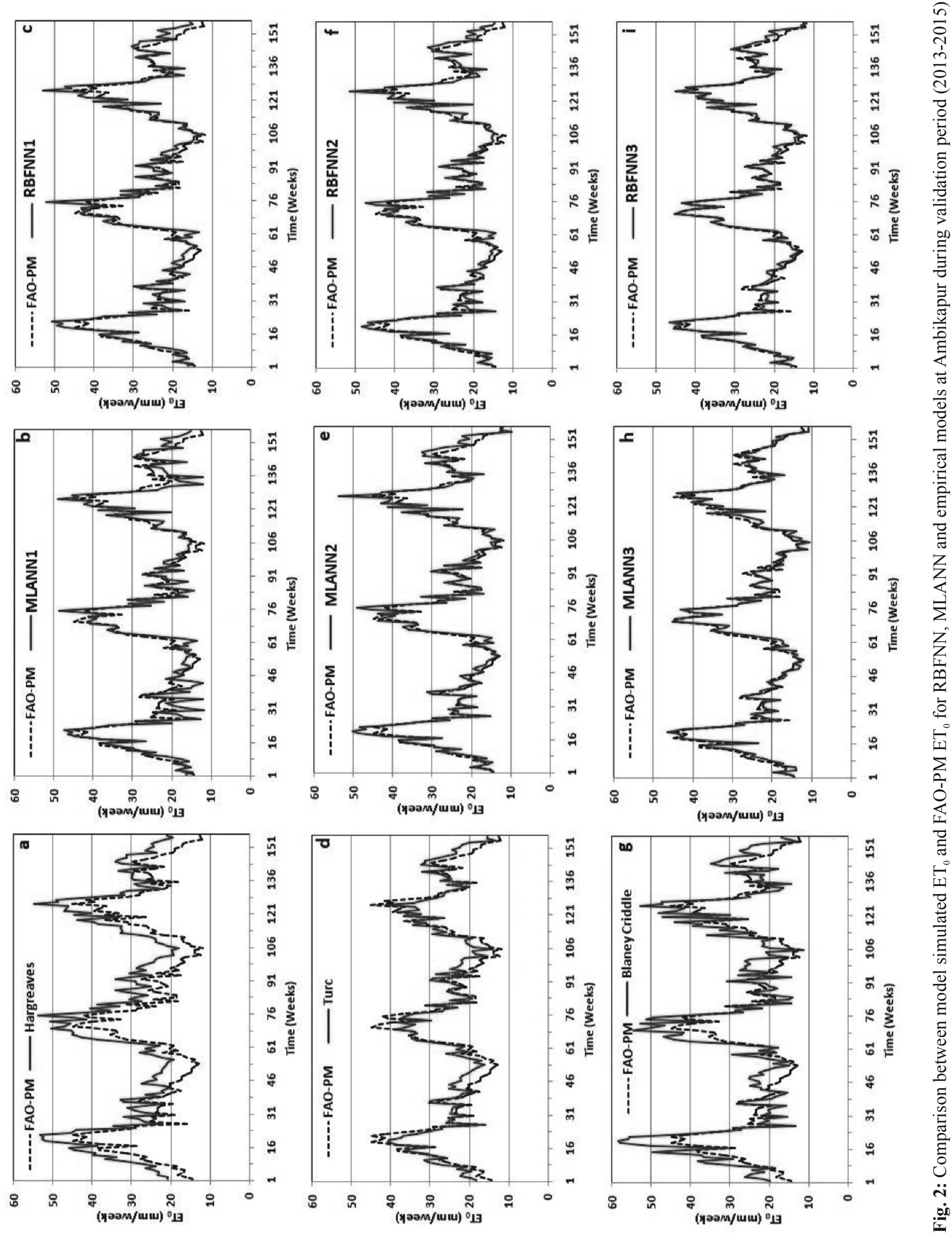

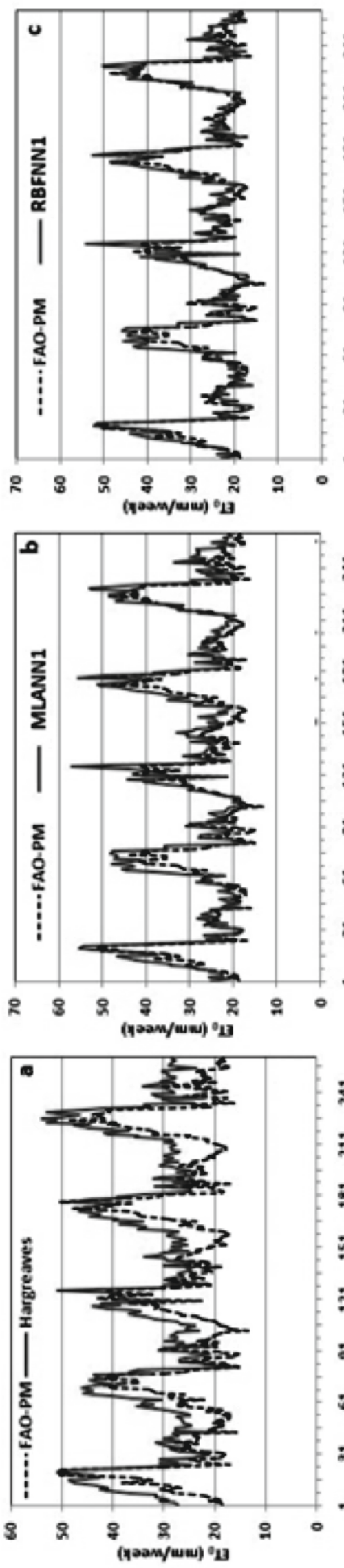
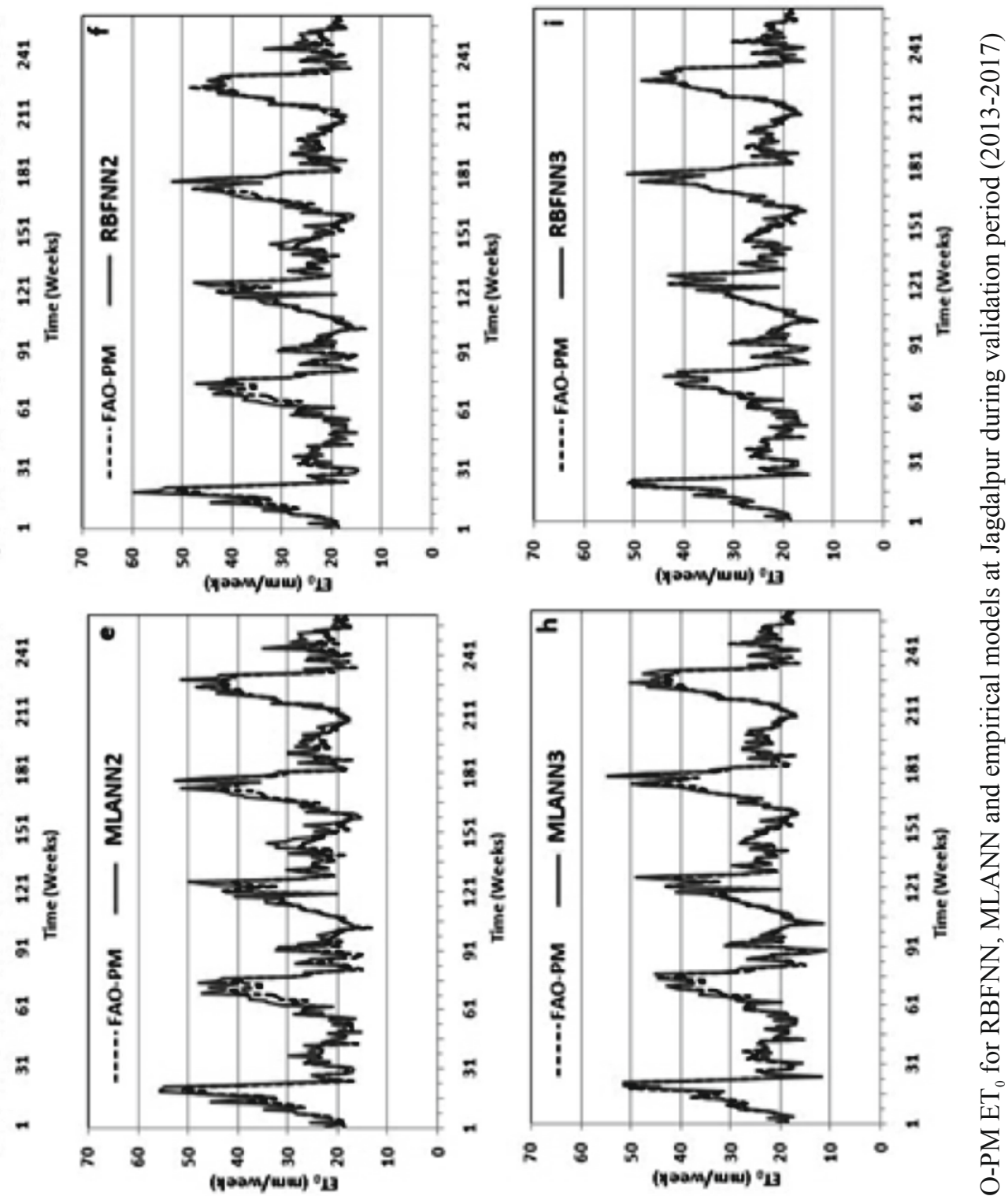

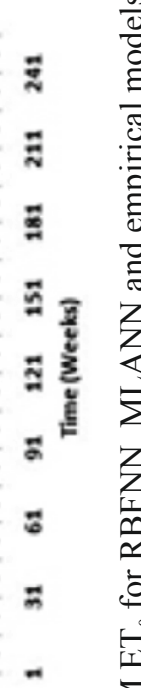
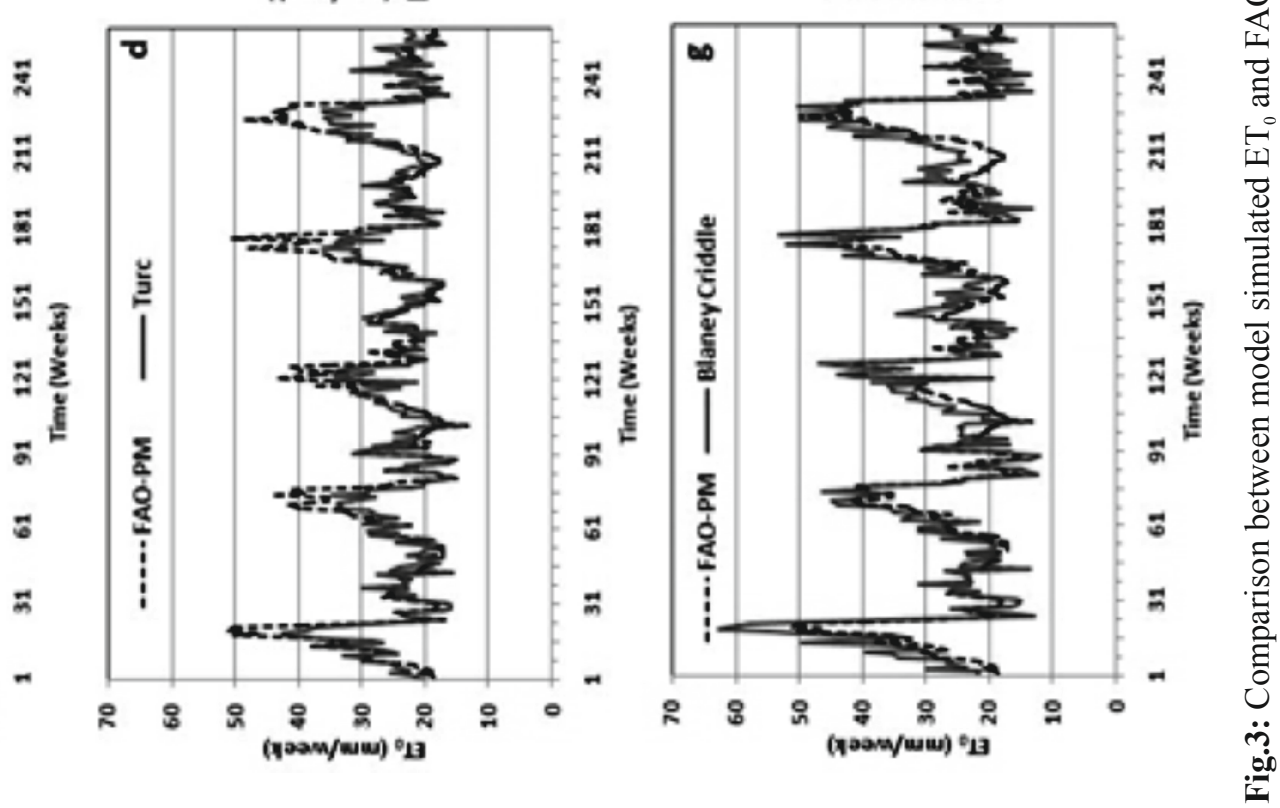

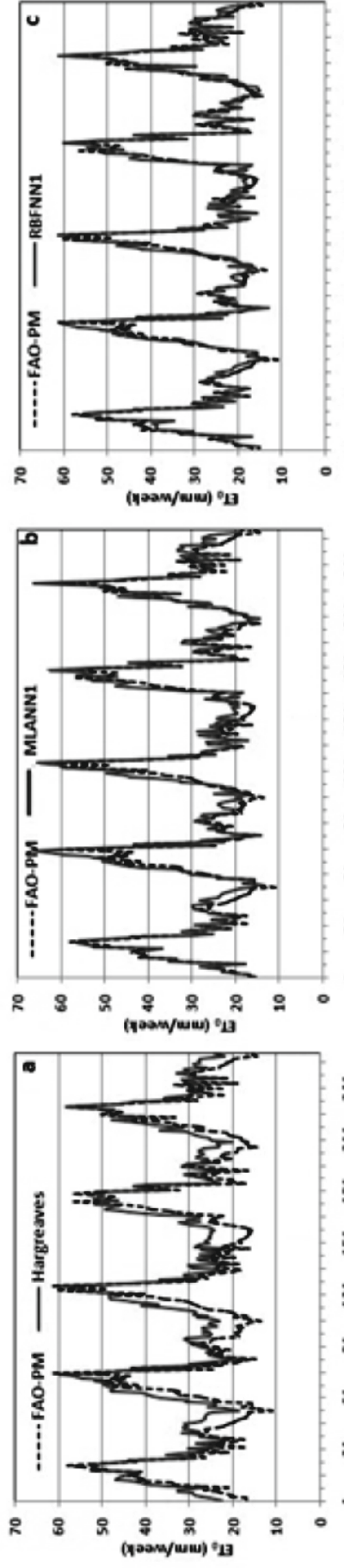
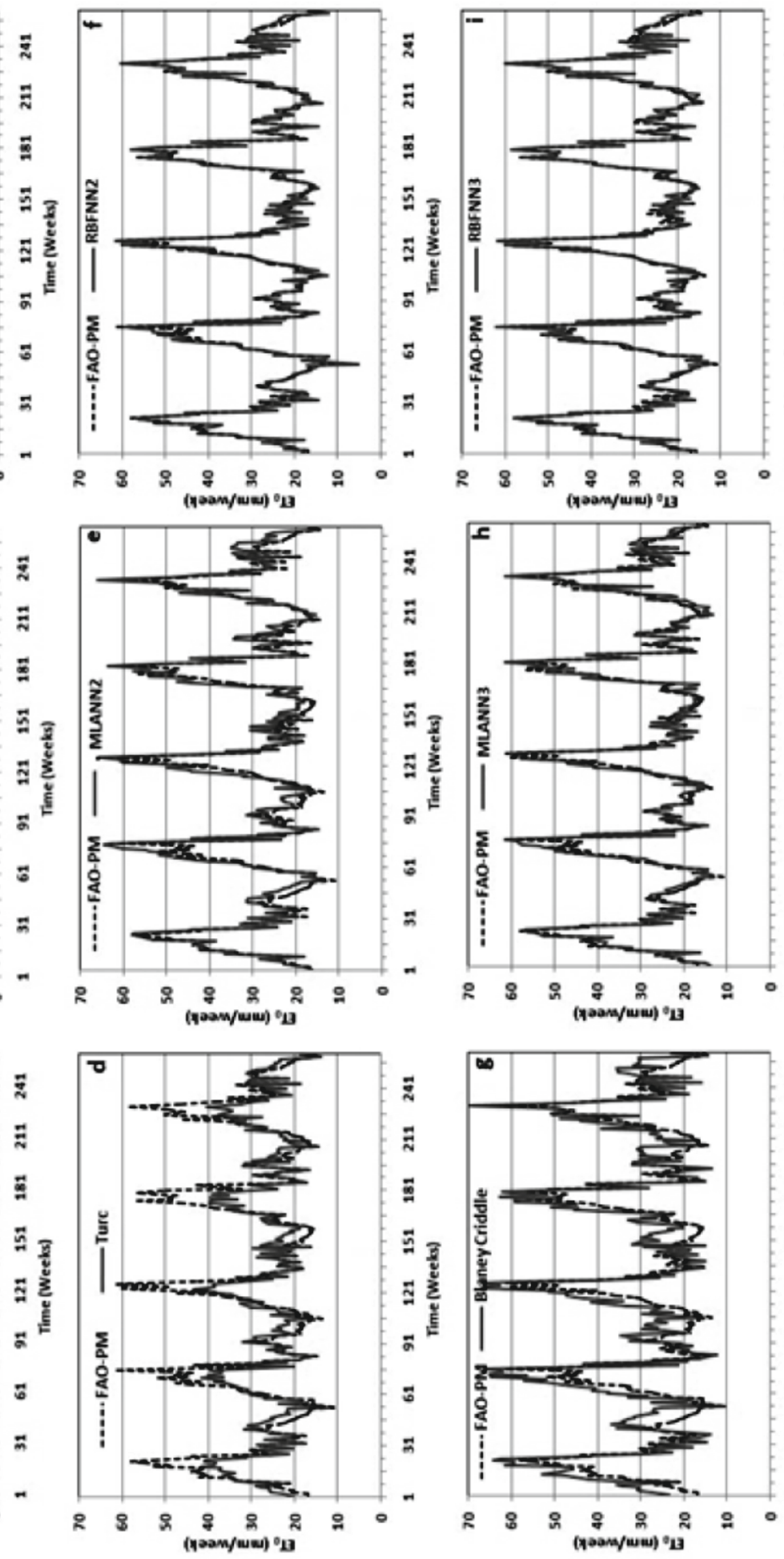

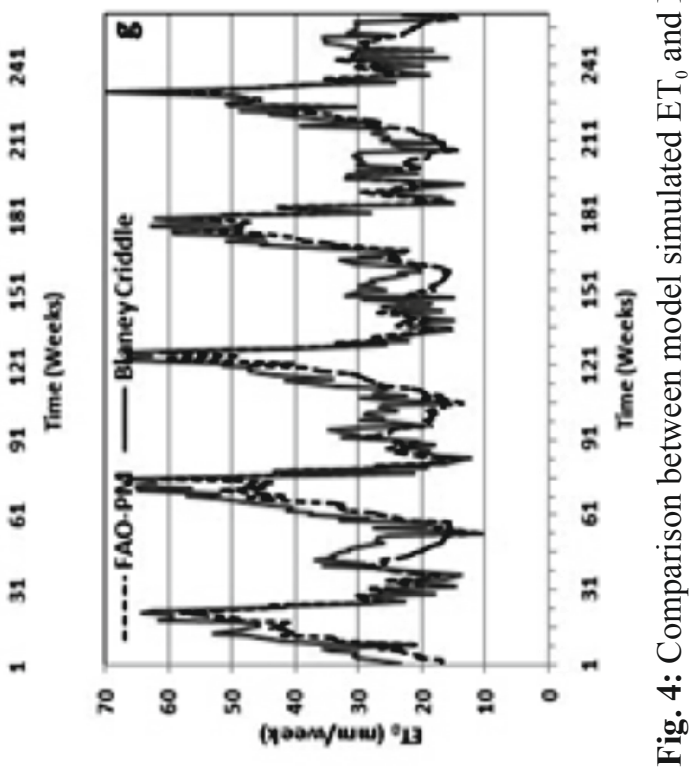



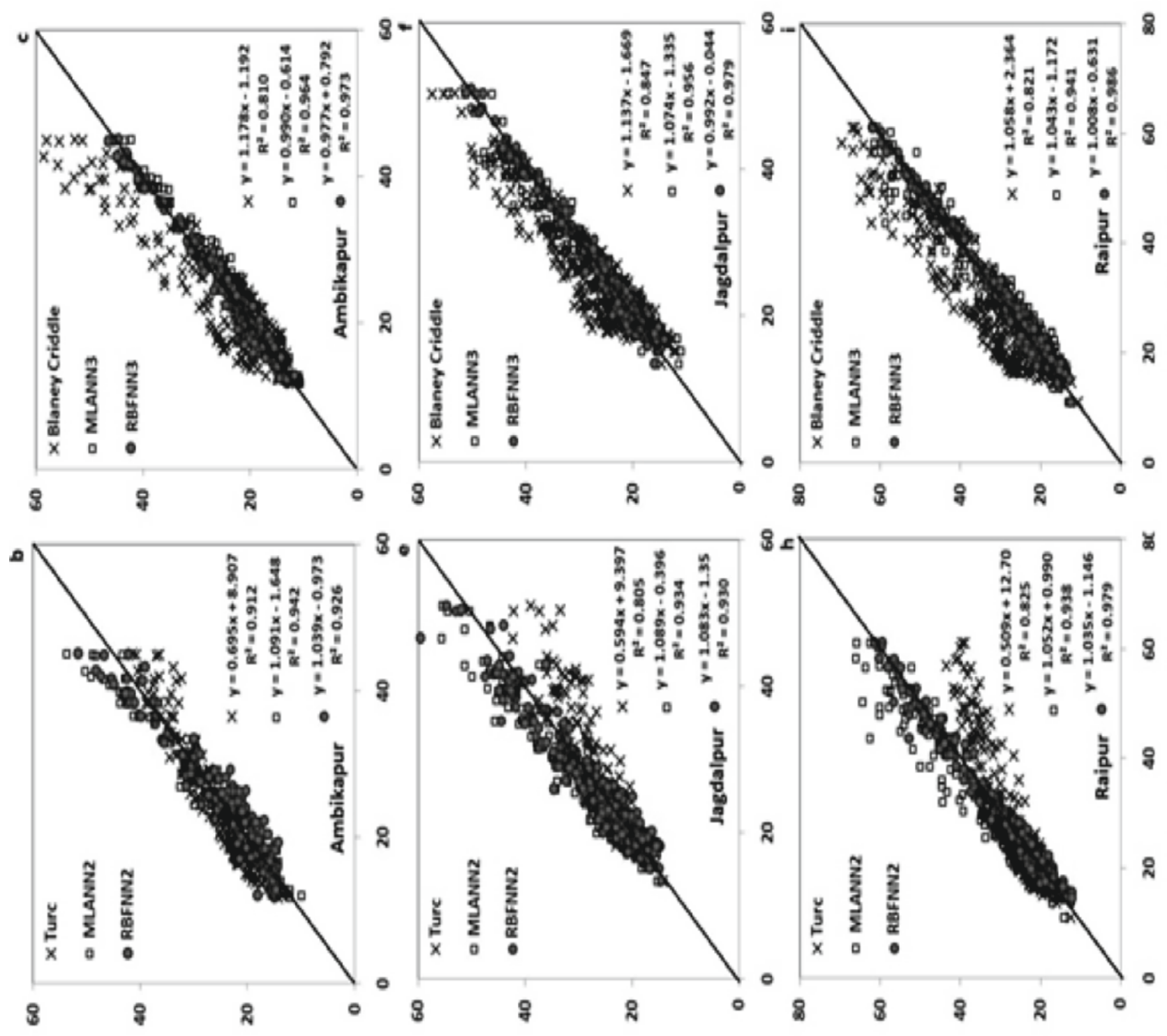

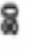

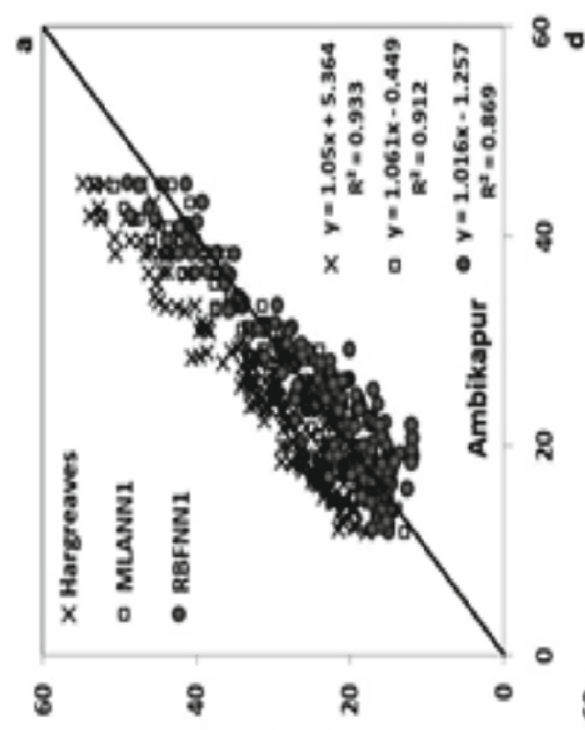

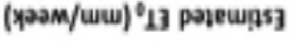

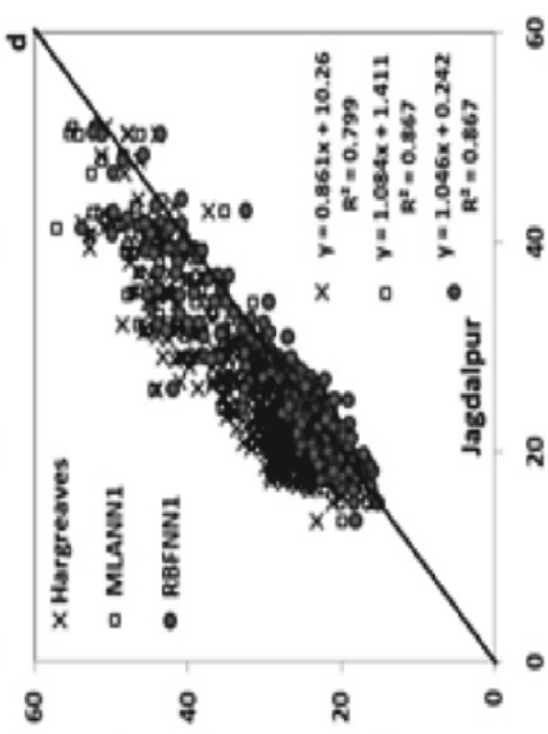

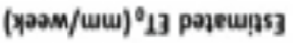

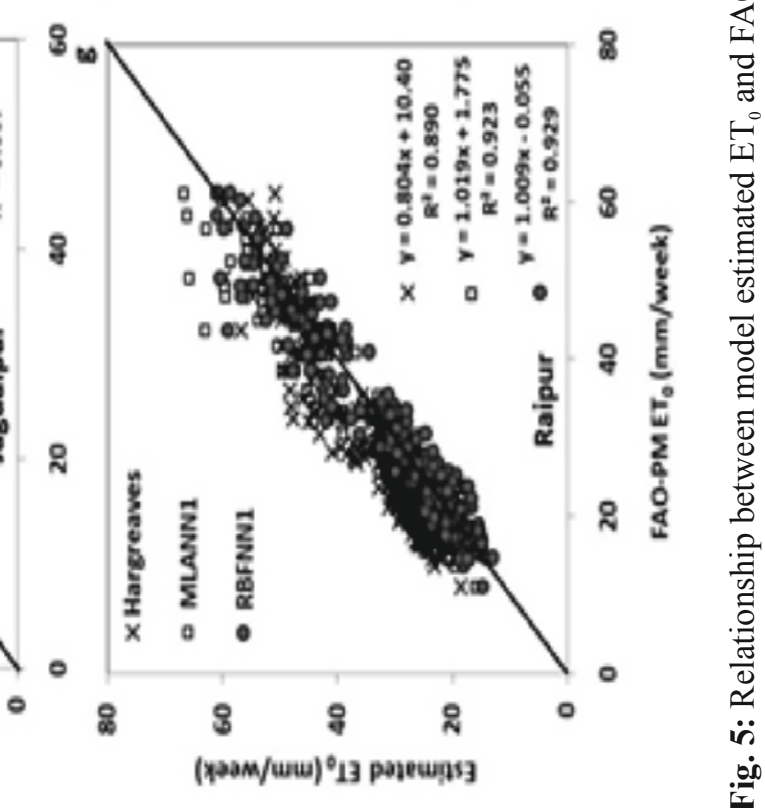


factor for the same is computed 0.312 only. Hence, both $\mathrm{R}^{2}$ and $\mathrm{EF}$ together gives a fair idea about model performance and confirms the superiority of the proposed RBFNN model over MLANN and empirical approaches at all the locations. Higher $\mathrm{R}^{2}$ and $\mathrm{EF}$ values are represented in bold numbers in Table 6. Further pictorial representation of relationship between modeled $\mathrm{ET}_{0}$ and FAO-PM ET $\mathrm{F}_{0}$ through scattered plots along with corresponding linear equations are shown in Fig. 5 (a to i). It can be clearly visualized from the scattered plots that $\mathrm{ET}_{0}$ estimates of proposed RBFNN models are more closely related with FAO-PM ET ${ }_{0}$ along the identical trend line as compared to corresponding MLANN and empirical approach in all the locations.

\section{CONCLUSION}

The investigation was carried out with an objective to examine the potential of RBFNN models for estimating FAO$\mathrm{PM} \mathrm{ET}_{0}$ with available climatic data. Based on the various performance evaluation criteria considered for model comparison, it is concluded that the proposed RBFNN models clearly demonstrated their superiority and produced significantly better results than Hargreaves, Turc and BlaneyCriddle empirical approaches with minimum available input data. The other machine learning model MLANN considered for this study is also found capable of estimating FAO-PM ET with considerable accuracy as compared to equivalent empirical approach. However among these two approaches RBFNN demonstrates higher predictive accuracy and may be used in place of Hargreaves, Turc and Blaney-Criddle to compute FAO-PM ET ${ }_{0}$ equivalent estimates in the all the three ACZs under investigation. In future these neural network based models may be included as subroutine for $\mathrm{ET}_{0}$ estimation instead of other empirical models while developing crop weather models, especially when sufficient data is not available for computation of FAO-PM ET ${ }_{0}$.

\section{REFERENCES}

Allen, R., Pereira, L. S., Raes, D. and Smith, M. (1998). Crop evapotranspiration - guidelines for computing crop water requirements, FAO Irrigation and Drainage Paper No.56. FAO (p 300). https://doi.org/10.1016/j. eja.2010.12.001

Broomhead, D. and Lowe, D. (1988). Multivariable Functional Interpolation and Adaptive Networks. Complex Sys., 2:321-355.

Chauhan, S. and Shrivastava, R.K. (2009). Performance evaluation of reference evapotranspiration estimation using climate based methods and artificial neural networks. Water Resour. Manage., 23(5):825-837.

Dar, E.A., Yousuf, A. and Brar, A.S. (2017). Comparison and evaluation of selected evapotranspiration models for Ludhiana district of Punjab. J. Agrometeorol., 19(3): 274-276.

Doorenbos, J. and Pruitt, W.O. (1977). Guidelines for predicting crop water requirements. Irrigation and drainage paper No 24, Second edition, Food and Agriculture Organization, Rome, 156p.

Feng, Y., Cui, N., Zhao, L., Hu, X. and Gong, D. (2016). Comparison of ELM, GANN, WNN and empirical models for estimating reference evapotranspiration in humid region of Southwest China. J. Hydrol., 536:376-383. https://doi.org/10.1016/j. jhydrol. 2016.02.053.

Gocić, M., Motamedi, S., Shamshirband S., Petković, D., Ch, S., Hashim, R. and Arif, M. (2015). Soft computing approaches for forecasting reference evapotranspiration. Comput. Electron Agric., 113:164173. https://doi.org/10.1016/j.compag.2015.02.010

Hargreaves, G.L., Hargreaves, G.H. and Riley, J.P. (1985). Agricultural, benefits for Senegal River Basin. J. Irrig. Drain. Engg.(ASCE), 111:113-124.

Haykin S. (1998). Neural Networks - A Comprehensive Foundation. Second ed. Prentice-Hall, Upper Saddle River, NJ; 26-32.

Khedkar, D.D., Singh, P.K. and Bhakhar, S.R. (2019). Estimation of evapotranspiration using neural network approach. J. Agrometeorol., 21(2): 233-235.

Landeras, G., Ortiz-Barredo, A. and López, J. J. (2008). Comparison of artificial neural network models and empirical and semi-empirical equations for daily reference evapotranspiration estimation in the Basque Country (Northern Spain). Agric. Water Manage., 95(5):553-565. https://doi.org/10.1016/j. agwat.2007.12.011.

Mallikarjuna, P., Jyothy, S. A. and Sekhar Reddy, K. C. (2012). Daily Reference Evapotranspiration Estimation using Linear Regression and ANN Models. J. Inst. Engg. (India): Series A, 93 (4): 215-221. https://doi.org/10.1007/s40030-013-0030-2.

Nash, J.E. and Sutcliffe J.V. (1970). River flow forecasting through conceptual models part I - A discussion of principles. J. Hydrol., 10(3):282-290.

Phad, S.V., Dakhore, K.K. and Sayyad, R.S. (2019). Comparison of different methods for estimation of reference evapotranspiration at Parbhani, Maharashtra. J. Agrometeorol., 21(2):236-238.

Turc, L. (1961). Evaluation des besoins en eau d'irrigation, evapotranspiration potentielle, formule climatique simplifice et mise a jour. (in French). Ann. Agron., 12: 13-49.

Shiri, J., Nazemi, A.H., Sadraddini, A.A., Landeras, G., Kisi, O., Fakheri Fard, A. and Marti, P.(2014). Comparison of heuristic and empirical approaches for estimating reference evapotranspiration from limited inputs in Iran. Comput. Electron Agric., 108:230-241. https://doi.org/10.1016/j. compag.2014.08.007. 